\title{
Design and Application of Wireless Sensor Network Monitoring Software Based on LABVIEW
}

\author{
https://doi.org/10.3991/ijoe.v13i05.7047 \\ Xue-Wen Yu \\ Shunde Polytechnic, Guangdong, China \\ lkauezp1076276@126.com
}

\begin{abstract}
Wireless multi-point real-time environmental monitoring system based on LabVIEW is composed of three parts: wireless environment information collection node, communication gateway, and host computer monitoring system. The purpose of this study is to explore the application of wireless monitoring technology in industry. Since that it is at the stage of research feasibility, various sensors used for the applications select the level limited to the ordinary teaching using sensor. AGV uses vehicle manipulator developed by Wuhan Depushi Technology Company and some sensors are simulated. The results of simple basic experiments showed that the wireless module can achieve point to multipoint communication. It is concluded that the monitoring interface can simultaneously process the data of a simulated pipeline terminal node with a simulated AGV data and make them work in a closed loop state.
\end{abstract}

Keywords-LabVIEW, environmental monitoring system, sensors

\section{Introduction}

In the manufacturing field, the application of the sensor is quite common, and it is difficult to realize the intelligence without sensor. However, if these intelligent devices equipped with sensor have not realized mutual communication, its intelligent effect will be affected [1]. The emergence of wireless sensor network technology makes up this defect, and through the wireless network, intelligent equipment is connected together. At the same time, it makes the intelligent equipment originally not linked to network become more intelligent.

The focus of this design is to make AGV work automatically. Use the wireless network transmission AGV and the working state data of the pipeline terminal, and through the remote monitoring interface written by LABVIEW, process the data, which can make AGV become more intelligent. The wireless transmission function of the design is to achieve by making use of the XBee module, while AGV is to simulate with the use of vehicle manipulator and some sensors [2]. The monitoring interface written by LABYIEW can make the entire work process in a closed loop operating state. Staffs can also understand the current working state of each AGV and each line through the monitoring interface; when an emergency occurs, the staffs can also make AGV stop working by the emergency brake button in the monitoring interface. 
Through the wireless monitoring design, we can achieve the intelligence of some links in the production, but also protect the right distribution of a large number of various parts [3]. Compared to traditional industrial automation, the advantage of this design is that AGV can be used as a human being to decide when to call a control program to work, rather than just relying on the specified program to run mechanically.

\section{State of the art}

With the continuous improvement of technology, the cost of sensor nodes is decreasing and the function is stronger. Compared with the wired network, wireless sensor network has many advantages. Its application is very extensive. At this stage, it is mainly used in the military field, environmental monitoring and industrial fields.

In 2001, the US Army proposed a "smart sensor network communication" program. The US Navy also established a "sensor network system" research project. These applications are based on wireless sensor networks. It can be more detailed and accurate to detect combat information, which makes a qualitative leap in the ability of intelligence reconnaissance and acquisition. In March 2001, the US Defense Advanced Research Projects Agency dropped a wireless sensor with a magnetometer mounted along the highway, and thus calculated the direction and speed of the vehicle. In July 2003, University of California at Berkeley deployed 100 wireless sensors in a square area. They use the respective magnetometer to monitor the activity of the pre-placed car A. Then, it transfers the information to another automatic trolley, and moves it along with the car A.

In the Hawaiian Volcanoes National Park, the University of Hawaii paved a wireless sensor network to monitor microclimate changes in the locus of extinct plants. In the grove of Sonoma in northern California, scientists have built a system. The system consists of a plastic sensor that is bundled with redwood tree branches and trunk. Based on the collected data, the system can draw a detailed chart to illustrate the microclimate changes around these trees. In China's Dunhuang Mogao Grottoes, scientists in the United States and Japan use wireless sensor networks to monitor the humidity and light intensity inside the cave. According to the collected data, people take timely and appropriate protective measures, such as ventilation, etc., thereby reducing the erosion of saline groundwater damage to the cave.

BP uses wireless sensor networks to remotely monitor the occupancy of liquefied petroleum gas cylinders for industrial users. General Motor has installed an inventory tracking system based on wireless sensor networks, which can track the entire process from component suppliers to car buyers in real time. It improves the observability of the operation and utilization of raw materials, thereby enhancing the efficiency of the supply chain.

At present, many famous universities and enterprises at home and abroad have researched and developed the wireless sensor networks from different aspects. They have developed a number of monitoring software. Such as SNAMP of the Institute of Computer Science, Chinese Academy of Sciences, Chengdu Antenna Long Commu- 
nication Technology Co., Ltd. Antenna Longwei ZIGBEE wireless network monitoring platform, SpyGlass of Luebeck University in Germany, Mote View of Crossbow, TinyViz of University of California, and EmStar of Los Angeles. Intel's EcoSense project team is deploying a pre-maintenance system that uses a wireless sensor network to detect semiconductor production machines. It can analyze the vibration signal of the water treatment equipment, and use it for maintenance operations.

Through a comprehensive analysis, these monitoring platforms have three defects: (1) They do not use TCP/IP communication protocol, which is not conducive to the application of TCP/IP in the field of industrial control. (2) Most of the nodes in the network are static nodes, and they do not consider the dynamic state of the nodes. (3) They have a strong pertinence, which is not conducive to the selection of scientific research and secondary development. Therefore, this paper develops a visual monitoring platform that can monitor dynamic nodes. Its eminent advantages concentrate on its wide adaptability. Aiming at the changing characteristics of wireless sensor network topology, we designed the wireless sensor network monitoring software which adapts to this characteristic. In the windows system platform, we use Labview as the main tool to realize the function of the monitoring software. Based on the experimental platform, the function of the monitoring software is tested, and the test results are analyzed in detail. Finally, the functions of the system are verified.

\section{Scheme design}

This design is to make use of wireless communication technology and LABVIEW software, to achieve the effect of using automatic control (Automated Guided, AGV) to work in the production. Vehicles equipped with a number of sensors are called P7 AGV. They can automatically complete the distribution of raw materials, finished products and semi-finished products in the factory. In addition, they can also conduct self-navigation and automatically avoid obstacles. When the end of the assembly line needs to deliver semi-finished products or finished products, AGV will automatically [4] complete the distribution work. At the same time, on the remote end PC machines, we can observe the running state of the AGV and the working condition of end of the assembly line through the monitoring interface. The whole process is working in a closed state, and the diagram of the simulation in the design is shown in Figure 1.

The entire wireless monitor design is composed of AGV, fixed terminal nodes and remote monitoring center. In the entire network, each node communicates through the wireless network, and the monitoring center processes related data to realize the intelligence. The whole process does not require human intervention, the staffs only need to monitor the working condition and deal with some emergencies in the end through the PC machine.

(1) Automatic guided vehicle

AGV refers to the vehicles that have guiding equipment and can autonomously work, mainly used in the field of intelligent industry. Automatic guided vehicle in this design is to achieve its basic intelligence work using on-board sensors, but also can communicate with remote monitoring center through the wireless network, and auto- 
matically control the AGV working by the data in the remote monitoring center processing network, which is the function that the traditional AGV does not have [5].

(2) Fixed terminal node

The detection terminal node of the raw material area is the detection of the amount of raw material piling up, and the function of the semi-finished product fixed terminal node and the finished product detection fixed terminal node is similar to that of the fixed terminal node in the raw material area.

(3) Remote PC monitoring center:

The editing environment of the existing PC monitoring interface is very rich. The editing environment used in the design is LABVIEW developed by NI (National Instruments) company.
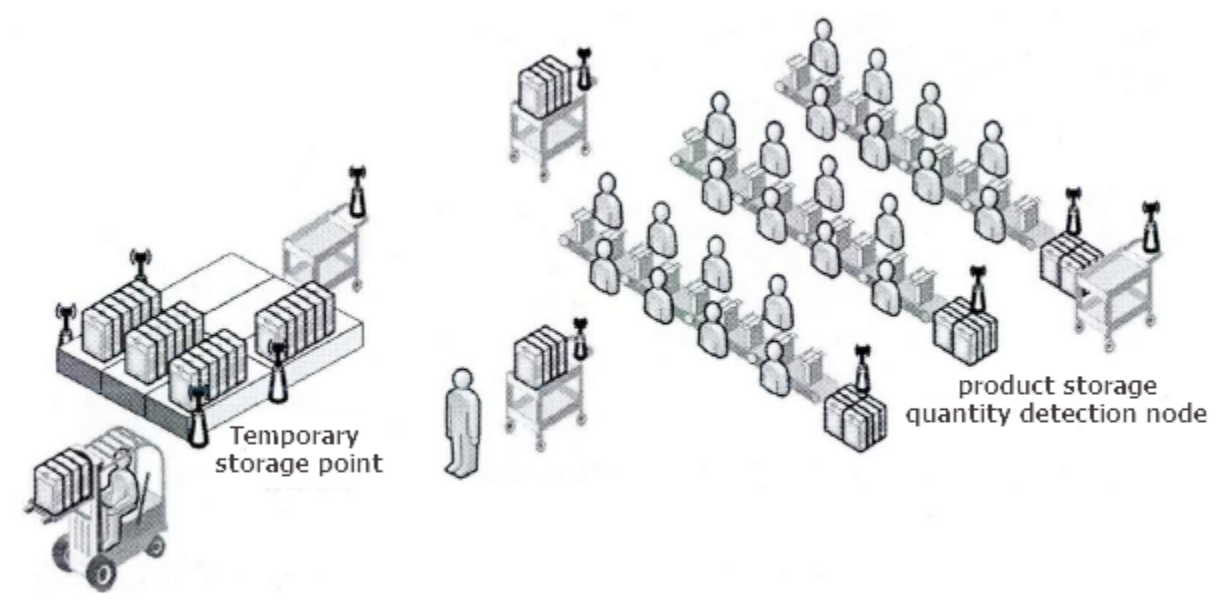

Fig. 1. Schematic diagram of wireless monitoring design

\section{System hardware design}

\subsection{Introduction to sensors}

The sensors selected in the design include ultrasonic sensors, infrared fast track sensor, and pressure sensor, to achieve the function of the design through the acquisition and processing of the sensor data.

(1) Ultrasonic sensor

The ultrasonic module selected by the design is the ultrasonic module developed by Parallax. The measuring range is $2 \mathrm{~cm}$ to $3 \mathrm{~m}$, the working voltage is $5 \mathrm{~V}$ DC electricity, and the working temperature is 0-70 DEG C. It is a simple and practical dual probe ultrasonic sensor module, as shown in Figure 2, ultrasonic module timing diagram. 


\begin{tabular}{|c|c|c|c|c|}
\hline- & Host Device & Input Trigger Pulse & $t_{\text {out }}$ & $2 \mu \mathrm{S}(\mathrm{min}), 5 \mu \mathrm{S}$ typical \\
\hline- & PING))) & Echo Holdoff & $\mathrm{t}_{\text {holdoff }}$ & $750 \mu \mathrm{s}$ \\
& Sensor & Burst Frequency & $\mathrm{t}_{\text {aurst }}$ & $200 \mu \mathrm{s} @ 40 \mathrm{kHz}$ \\
& Echo Return pulse Minmum & $\mathrm{t}_{\mathrm{IN}-\mathrm{MIN}}$ & $115 \mu \mathrm{s}$ \\
& Echo Return pulse Maxmum & $\mathrm{t}_{\mathrm{IN}-\mathrm{MAX}}$ & $18.5 \mu \mathrm{s}$ \\
& & Deley before next & & $200 \mu \mathrm{s}$ \\
\hline
\end{tabular}

Fig. 2. Ultrasonic module timing diagram

It cannot normally work mainly in 3 situations: (1) beyond the measurement range; (2) the angle between the object to be measured and the module is less than 45 degrees, and in this case ultrasonic cannot be reflected back to the module [6]; (3) the measured object is too small.

(2) Infrared fast track sensor

At present, there are many kinds of navigation methods of AGV at home and abroad, which are mainly divided into laser navigation, electromagnetic navigation, optical navigation, RFID navigation and so on. This scheme uses the infrared fast track sensor, which belongs to the category of optical navigation. The design makes use of Parallax Quick Track Infrared (QTI) sensor module. The schematic diagram is shown in Figure 4.

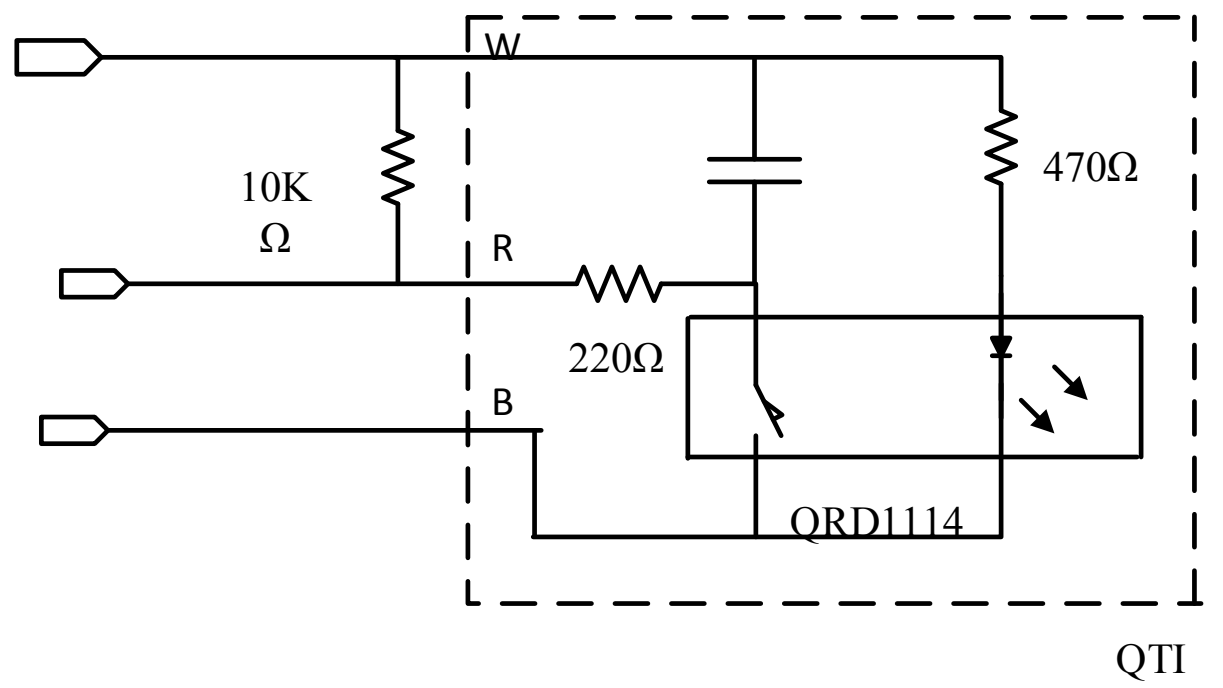

Fig. 3. QTI schematic 
(3) Pressure sensor

The pressure sensor used in this program is called a (Hexi Force sensor, which is a sensor to measure the stress of the contact surface, which belongs to the resistance type pressure sensor. When the contact surface is not under pressure, the resistance is more than $20 \mathrm{M} \Omega$; when the contact surface is pressured, the resistance is only $200 \mathrm{~K}$ $\Omega$ or so.

\subsection{Introduction to wireless module}

(1) XBee wireless module

The main work of the XBee module is in $868 \mathrm{MHz}, 900 \mathrm{MHz}, 2.4 \mathrm{GHz}$ these 3 bands, and the selection of the RF chip currently comes from two companies: S1 version selects Freescale company's chip; S2 version selects the Ember company's chip. It also has 4 forms of antenna optional: Wire, U. FL, RPSMA, and Chip.

(2) Working principle of XBee wireless module

The communication mode of XBee wireless communication module is the serial communication mode. The difference is that the serial communication does not need the cable as a communication medium, but the communication medium is changed for the air, which is also known as transparent transmission [7]. XBee wireless communication module uses asynchronous serial communication (UART). Each data is composed of a low level start bit, 8-bit data and a high level P61 end bit, whose data structure is shown in Figure 5.

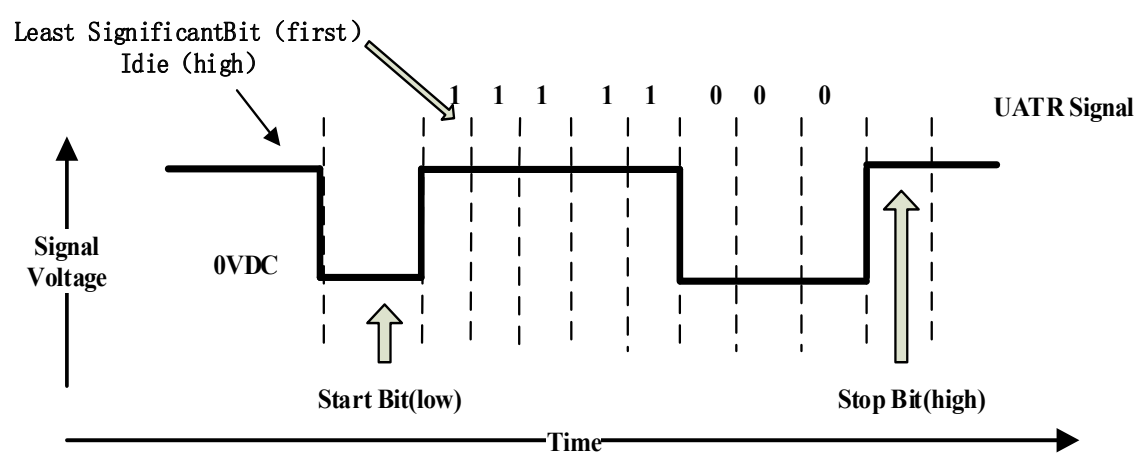

Fig. 4. Asynchronous serial communication data structure of XBee wireless communication module

(3) Packet structure

XBee wireless communication module packet structure can be divided into two kinds, one is the API mode, the other is the custom mode. A API model data packet can be composed of one-byte data packet start bit (0X7E), two bytes' data packet length bit, function data (FD) of several number of bytes and a byte packet detection 
bit, wherein the data packet detection bit values can be obtained according to the formula $\mathrm{CS}=\mathrm{OXFF}-\mathrm{FD}$. API mode packet structure example is shown in Figure 6.

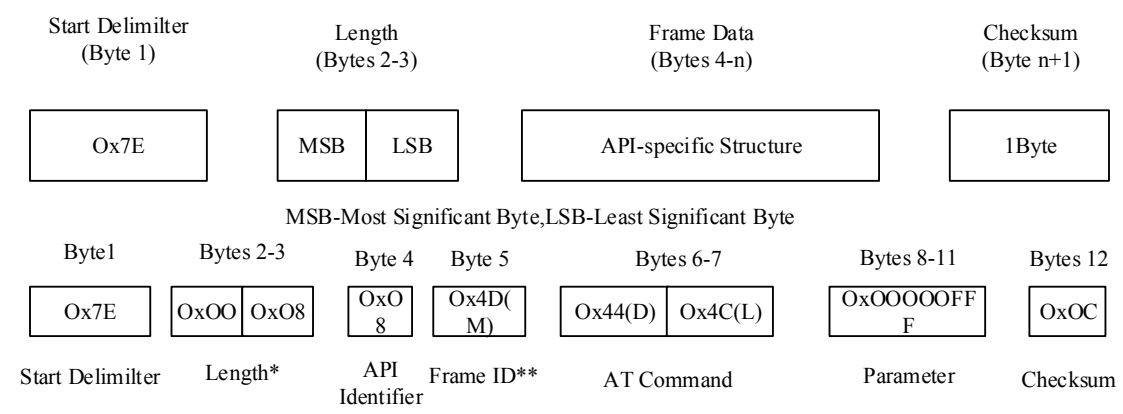

Fig. 5. API pattern packet structure example

\subsection{Fixed terminal node}

The function of the fixed terminal node in the design is used to monitor the situation of the pipeline terminal storage amount, and to send the information to the remote PC monitoring center. The monitoring interface of the PC machine can display the situation of each pipeline terminal storage amount, and according to the situation to determine whether it is necessary to send a dispatch command to AGV [8]. Since that the sensor used is not too accurate, the display of the amount of storage is only a way of switching amount, but not be displayed in a numerical way. The fixed terminal node workflow diagram is shown in Figure 7.

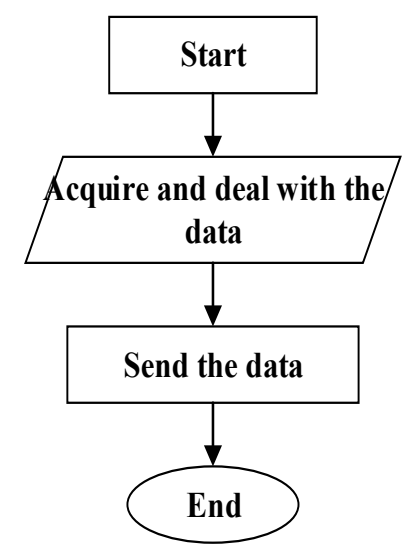

Fig. 6. Fixed terminal node workflow diagram 


\subsection{Simulation AGV}

AGV in the design makes use of vehicle manipulator, sensor and XBee module in the Wuhan Science and Technology company Depushi to simulate. The vehicle manipulator of Wuhan Science and Technology company Depushi is using STM32F103 as its main control chip [9]. The car is equipped with the ultrasonic module of Parallax company to realize the obstacle avoidance function, equipped with QTI sensor of Parallax company to realize the navigation function, equipped with a pressure sensor of Parallax company to monitor if there are goods on the car, and equipped with a XBee module of Digi International to realize wireless communication function. Because the design of analog AGV is not the focus of this paper, the basic working principle in the design is only introduced here.

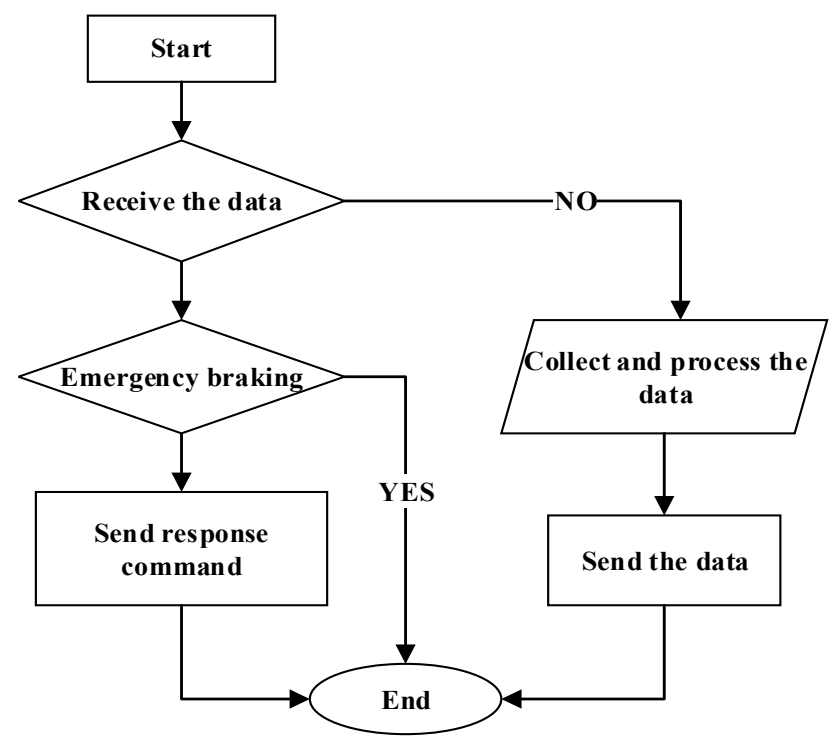

Fig. 7. AGV workflow diagram

If it is monitored that there are goods on the car, the AGV is not considered to be finishing the work; only when it is running to the designated location, and when it is detected that there are no goods on the car, it can be considered that the work is completed and in idle state. By sending and receiving data and MCU control, AGV can maintain the normal work under unattended conditions.

\section{$5 \quad$ System software design}

\subsection{Simulation AGV control program working principle}

Simulation AGV control program includes the driving program of vehicle manipulator and various sensors. Due to complicated procedures, here specific post code is 
not introduced, but to introduce the working principle of AGV control program by the flow direction of the program data and the literal interpretation. The working principle flow diagram of simulation AGV control program is shown in Figure 9.

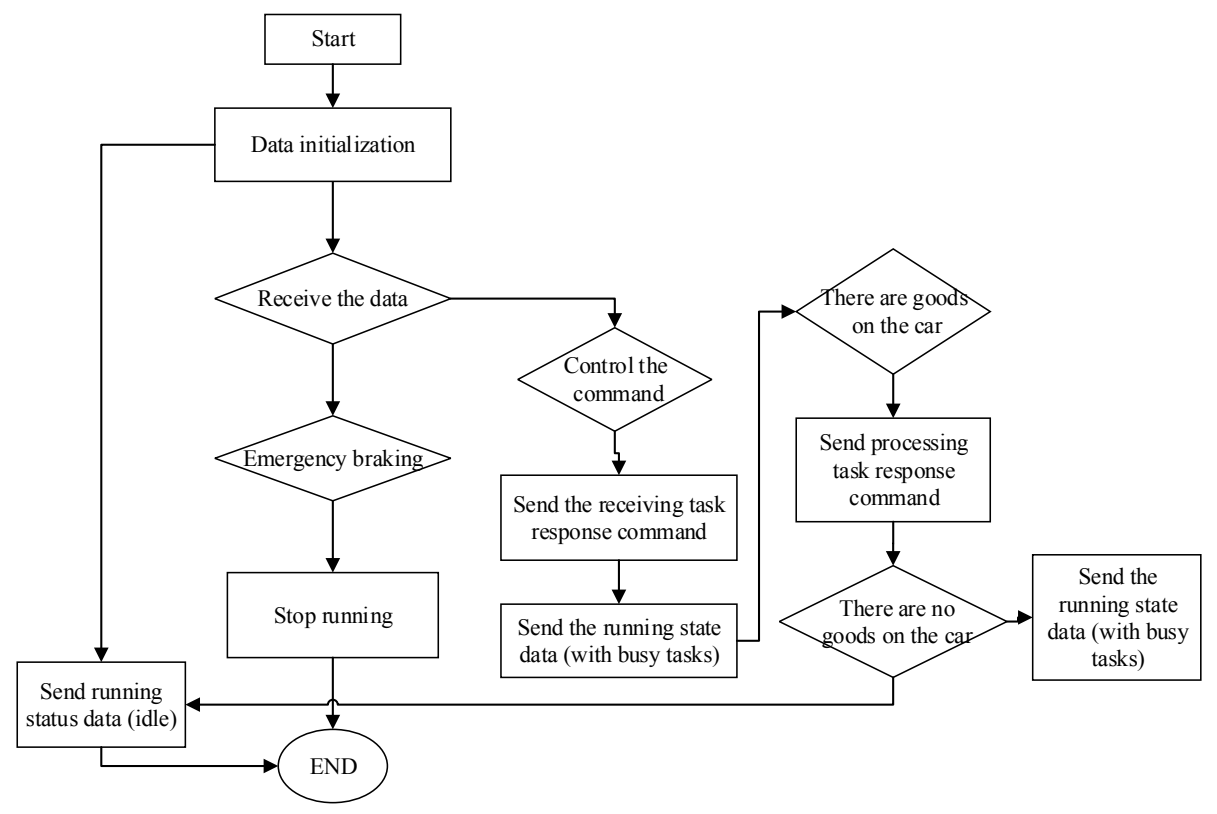

Fig. 8. The working principle flow diagram of simulation AGV control program

Simulation AGV receives data through the wireless module, and calls corresponding control procedure to make it work normally by taking the received data as the basis. In addition, it sends a response command packet and data packet of the running state to make the monitoring center accurately grasp the operation of various simulation AGVs and to ensure their normal operation.

\subsection{Wireless module settings}

The wireless communication part of this design makes use of the international XBee Di 802.15.4, which is a kind of simple wireless communication module. The lowest power consumption is only $\mathrm{ImW}$, the indoor communication distance is 30 meters, and the outdoor visual communication distance is 90 meters [10]. This network topology that the design uses is the star topology, XBee module of remote PC machine represents the center node, intelligent $\mathrm{AGV}$ and fixed terminal node is other nodes in a wireless network, and the center node can communicate with any other node, while other nodes cannot communicate.

XBee module configuration is relatively simple. We can use the free X-CTU software provided by Digi International to configure. 


\subsection{Monitoring interface}

The main function of the monitoring interface is to replace human beings for monitoring and controlling of the entire process, which is also one of the core parts of intelligence. The main work of the monitoring interface includes monitoring the sensor data, processing the received data, sending corresponding control commands according to the results of processing, displaying the working state of simulation AGV and relevant sensor data.

(1) Monitoring interface design environment

LABVIEW is a graphical development platform developed by NI company, which is programmed by using $\mathrm{G}$ (Graphic) language. The biggest feature of LABVIEW is that developers can complete the development in the basic control library provided by LABVIEW, which is generally called virtual instrument. NI company provides a strong control library, which can help R \& D personnel to shorten the development cycle. Only through the basic settings can it be achieved.

(2) Working principle of monitoring interface

The intelligent $\mathrm{AGV}$ controlled by the monitoring interface has 9 units, and there are 3 lines. No. 1 to No. 3 intelligent AGV process the material of No.1 pipeline, No. 2to No. 4 intelligent AGV process the material of No.2 pipeline, and No. 7 to No. 9 intelligent AGV process the material of No.3 pipeline. The wireless monitoring design block diagram is shown in Figure 10. Intelligent AGV and fixed terminal send the monitoring information to the monitoring interface through the wireless network, the monitoring interface will first of all display the basic information in the PC machine, then process the received data and judge whether each line needs distribution operation. If there is a pipeline needs for distribution, then according to the working condition of intelligent AGV, each monitoring interface will schedule suitable intelligent AGV for the distribution (this important scheduling principle will be introduced in details in the following chapters); if it does not need the distribution, then nothing is sent, and the monitoring interface only displays the working information of each node.

When the intelligent AGV receives the goods receiving order, it will return a corresponding "intelligent AGV response command data packet", and this packet contains important information of scheduling principle. 


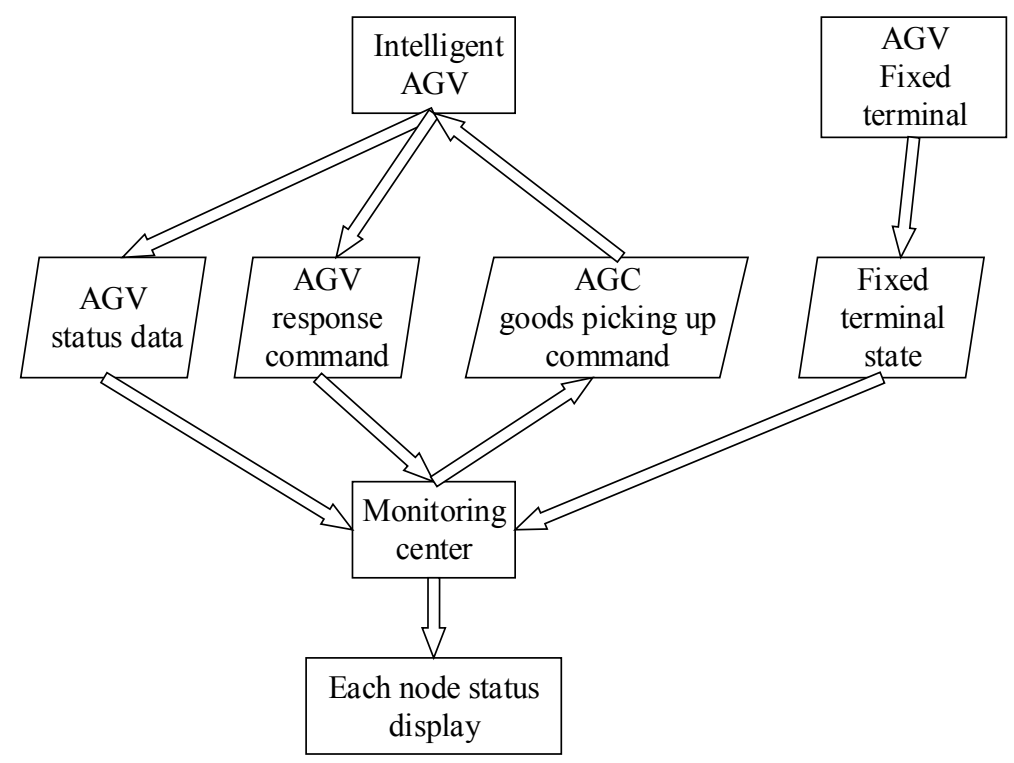

Fig. 9. Wireless monitoring design running diagram

(3) Monitoring interface packet

The data packet in the design united consists of 13 bytes, and contains a total of 5 forms: "intelligent AGV operation state data packet", "fixed terminal node data packet", "intelligent AGV control command data packet", "intelligent AGV response command data packet", and "emergency braking command packet".

Table 1. Intelligent $\mathrm{AGV}$ operation state data packet

\begin{tabular}{|c|c|c|c|c|c|c|c|}
\hline Start bit & Car number & task & Forward & stop & Backwards \\
\hline 9 & $1-9$ & $0 / 1$ & \multicolumn{2}{|c|}{$0 / 1$} & \multicolumn{2}{c|}{$0 / 1$} & \multicolumn{2}{|c|}{$0 / 1$} \\
\hline $\begin{array}{c}\text { With or } \\
\text { without } \\
\text { obstacles }\end{array}$ & $\begin{array}{c}\text { Manipula- } \\
\text { tor opera- } \\
\text { tion }\end{array}$ & $\begin{array}{c}\text { Mechanical } \\
\text { clip opera- } \\
\text { tion }\end{array}$ & $\begin{array}{c}\text { Whether } \\
\text { there is any } \\
\text { goods }\end{array}$ & $\begin{array}{c}\text { Voltage } \\
\text { (high) }\end{array}$ & $\begin{array}{c}\text { Voltage } \\
\text { (low) }\end{array}$ & Stop bit \\
\hline $0 / 1$ & $0 / 1$ & $0 / 1$ & $0 / 1$ & $0-9$ & $0-9$ & $0-9$ \\
\hline
\end{tabular}

Table 2. Fixed terminal node data packet

\begin{tabular}{|c|c|c|c|c|c|c|c|}
\hline Start bit & \multicolumn{2}{|c|}{$\begin{array}{c}\text { Pipeline } \\
\text { number }\end{array}$} & $\begin{array}{c}\text { Storage tank } \\
\text { condition }\end{array}$ & $\begin{array}{c}\text { Voltage } \\
\text { (high) }\end{array}$ & \multicolumn{1}{c|}{$\begin{array}{c}\text { Voltage } \\
\text { (low) }\end{array}$} & Reserved bit \\
\hline 8 & $1-3$ & \multicolumn{2}{|c|}{$0 / 1$} & $0-9$ & $0-9$ & \multicolumn{2}{|c|}{0} \\
\hline $\begin{array}{c}\text { Reserved } \\
\text { bit }\end{array}$ & $\begin{array}{c}\text { Reserved } \\
\text { bit }\end{array}$ & $\begin{array}{c}\text { Reserved } \\
\text { bit }\end{array}$ & $\begin{array}{c}\text { Reserved } \\
\text { bit }\end{array}$ & $\begin{array}{c}\text { Reserved } \\
\text { bit }\end{array}$ & $\begin{array}{c}\text { Reserved } \\
\text { bit }\end{array}$ & Stop bit \\
\hline
\end{tabular}




\begin{tabular}{|l|l|l|l|l|l|l|}
\hline 0 & 0 & 0 & 0 & 0 & 0 & $0-9$ \\
\hline
\end{tabular}

Table 3. Intelligent AGV control command data packet

\begin{tabular}{|c|c|c|c|c|c|c|c|}
\hline Start bit & Car number & $\begin{array}{c}\text { Material } \\
\text { signal }\end{array}$ & Reserved bit & Reserved bit & Reserved bit \\
\hline 7 & $1-9$ & 1 & \multicolumn{2}{|c|}{0} & \multicolumn{2}{|c|}{0} & 0 \\
\hline $\begin{array}{c}\text { Reserved } \\
\text { bit }\end{array}$ & $\begin{array}{c}\text { Reserved } \\
\text { bit }\end{array}$ & $\begin{array}{c}\text { Reserved } \\
\text { bit }\end{array}$ & $\begin{array}{c}\text { Reserved } \\
\text { bit }\end{array}$ & $\begin{array}{c}\text { Reserved } \\
\text { bit }\end{array}$ & $\begin{array}{c}\text { Reserved } \\
\text { bit }\end{array}$ & Stop bit \\
\hline 0 & 0 & 0 & 0 & 0 & 0 & 0 \\
\hline
\end{tabular}

Table 4. Intelligent AGV response command data packet

\begin{tabular}{|c|c|c|c|c|c|c|}
\hline $\begin{array}{c}\text { Reserved } \\
\text { bit }\end{array}$ & Reserved bit & $\begin{array}{c}\text { Reserved } \\
\text { bit }\end{array}$ & $\begin{array}{c}\text { Reserved } \\
\text { bit }\end{array}$ & $\begin{array}{c}\text { Reserved } \\
\text { bit }\end{array}$ & $\begin{array}{c}\text { Reserved } \\
\text { bit }\end{array}$ & Stop bit \\
\hline 0 & 0 & 0 & 0 & 0 & 0 & $0-9$ \\
\hline Start bit & Car number & $\begin{array}{c}\text { Task pro- } \\
\text { cessing }\end{array}$ & Reserved bit & Reserved bit & Reserved bit \\
\hline 6 & $1-9$ & 1 & 0 & 0 & 0 \\
\hline
\end{tabular}

Table 5. Emergency braking command packet

\begin{tabular}{|c|c|c|c|c|c|c|}
\hline Start bit & Data bit1 & Data bit2 & Data bit3 & Reserved bit & Reserved bit \\
\hline 5 & J-00 & 4 & 4 & 0 & \multicolumn{2}{|c|}{0} \\
\hline Reserved bit & Reserved bit & $\begin{array}{c}\text { Reserved } \\
\text { bit }\end{array}$ & Reserved bit & $\begin{array}{c}\text { Reserved } \\
\text { bit }\end{array}$ & $\begin{array}{c}\text { Re- } \\
\text { served } \\
\text { bit }\end{array}$ & Stop bit \\
\hline 0 & 0 & 0 & 0 & 0 & 0 & 7 \\
\hline
\end{tabular}

(4) Intelligent AGV scheduling VI

After judging which line to pick up the goods, it is necessary to make reasonable scheduling of intelligent AGV of assembly line needing to pick-up the goods. Figure 11 is the front panel diagram of No. 3 line "intelligent AGV scheduling VI". From the front panel diagram, it can be seen that, it is to make reasonable scheduling by judging which intelligent $\mathrm{AGV}$ is in idle. 


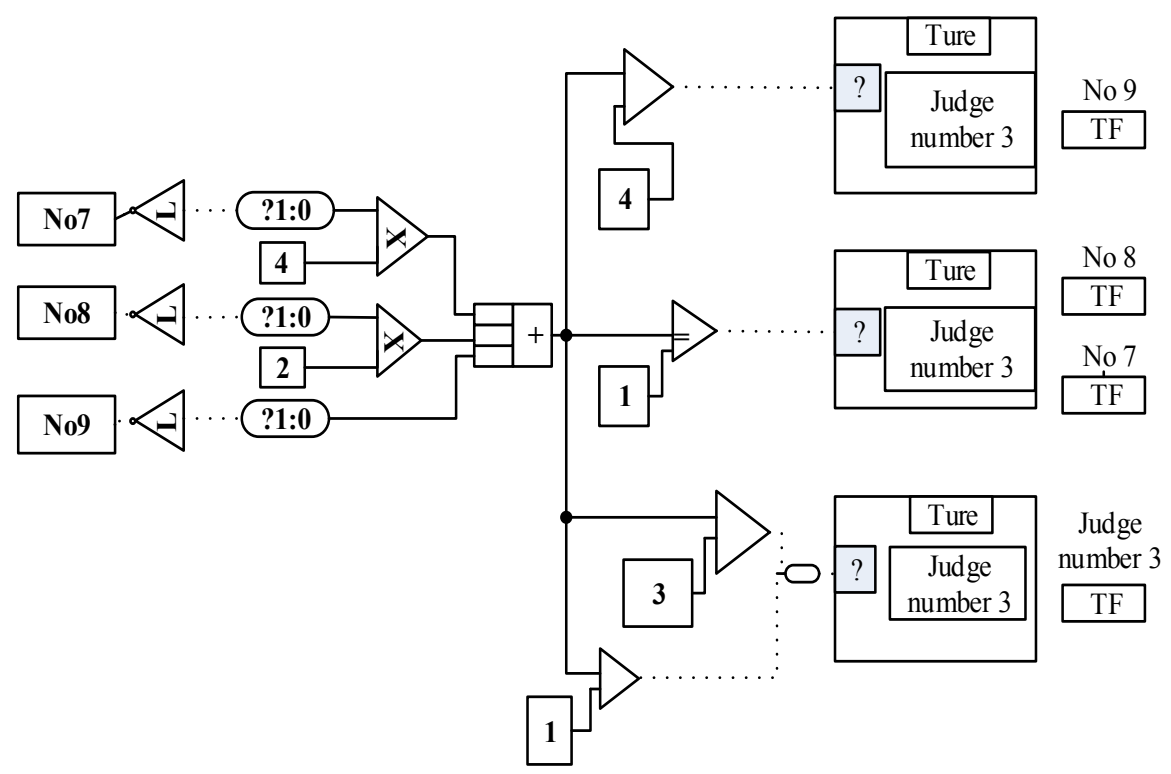

Fig. 10. The front panel diagram of No. 3 line "intelligent AGV scheduling VI"

\section{Conclusion}

Because the design of this paper is to achieve the effect of a closed loop, there are many considerations about the design architecture and design principles. The hardware part of this paper is the module and product simulation form, and the main part of AGV is composed of vehicle manipulator equipped with part of the sensor developed by Wuhan Science and Technology Depushi company, and the wireless communication part is realized by using XBee module. The software part is the focus of this paper, and the software in particular refers to the production of monitoring interface. It is equivalent to the brain of the design, which needs to be in accordance with certain rules to send, receive and process data correctly to achieve a closed loop effect.

This design is a feasible study, and many aspects are in the feasible stage. In the following, we can add the wireless network and Ethernet communication part. Of course, for the PC part, there are still many improvements. For example, we can also add storage function of the monitoring data, each data packet can continue to be simplified, and the scheduling mechanism of AGV also has very great improvement space. 


\section{$7 \quad$ References}

[1] Acero A R, Cano A M, Builes J A J. SCADA System for Detection of Explosive Atmospheres in Underground Coal Mines Through Wireless Sensor Network[J]. IEEE Latin America Transactions, 2014, 12(8):1398-1403. https://doi.org/10.1109/TLA.2014.7014506

[2] Bolanakis D E, Kotsis K T, Laopoulos T. Ethernet and PC -based experiments on barometric altimetry using MEMS in a wireless sensor network[J]. Computer Applications in Engineering Education, 2016, 24(3):443-455. https://doi.org/10.1002/cae.21722

[3] Chen C, Zhang T, Sun X, et al. Design and Application of Wireless Sensor Network Based on Signal Integrity Analysis[C]// IEEE, Intl Conf on Ubiquitous Intelligence and Computing and 2015 IEEE, Intl Conf on Autonomic and Trusted Computing and 2015 IEEE, Intl Conf on Scalable Computing and Communications and ITS Associated Workshops. IEEE Computer Society, 2015:808-813.

[4] Chen, W. T., \& Ho, C. H. (2016). Spectrum monitoring with unmanned aerial vehicle carrying a receiver based on the core technology of cognitive radio-A software-defined radio design. Journal of Unmanned Vehicle Systems, 5(1), 1-12. https://doi.org/10.1139/juvs2016-0011

[5] Chou J C, Chen J L, Liao Y H, et al. Fabrication and Characteristic Analysis of a Remote Real-Time Monitoring Applied to Glucose Sensor System Based on Microfluidic Framework[J]. IEEE Sensors Journal, 2015, 15(6):3234-3240. https://doi.org/10.1109/JSEN.20 15.2407910

[6] Datta, B., Durand, F., Laforge, S., Prakash, O., Esfahani, H. K., Chadalavada, S., \& Naidu, R. (2016). Preliminary Hydrogeologic Modeling and Optimal Monitoring Network Design for a Contaminated Abandoned Mine Site Area: Application of Developed Monitoring Network Design Software. Journal of Water Resource and Protection, 8(1), 46. https://doi.org/10.4236/jwarp.2016.81005

[7] Jalilian, M., Sariri, H., Parandin, F., Karkhanehchi, M. M., Hookari, M., Jirdehi, M. A., \& Hemmati, R. (2016). Design and implementation of the monitoring and control systems for distribution transformer by using GSM network. International Journal of Electrical Power \& Energy Systems, 74, 36-41. https://doi.org/10.1016/j.ijepes.2015.07.022

[8] Jiang, T., Yu, P., Liu, Y., Zhang, J., \& Zhen, S. (2016). Design of Monitoring System on QDQ2-1 Type Water Electrolysis Hydrogen Equipment. Open Journal of Safety Science and Technology, 6(03), 70. https://doi.org/10.4236/ojsst.2016.63006

[9] Yun-Jie, L., De-Tai, Z., Yan-Yu, W., \& Jia, Y. (2016, July). HIRFL Water Level Monitoring System Research and Design. In Instrumentation \& Measurement, Computer, Communication and Control (IMCCC), 2016 Sixth International Conference on (pp. 127-130). IEEE.

[10] Zhang, Y., \& Liang, L. (2016). A Distributed Infrared Temperature Monitoring System Based on Embedded Technology and Visualization Technology. International Journal of Smart Home, 10(2), 85-96. https://doi.org/10.14257/ijsh.2016.10.2.09

\section{Author}

Xue-Wen Yu is Associate Professor at Shunde Polytechnic, Guangdong, China (lkauezp1076276@126.com).

Article submitted 06 April 2017. Published as resubmitted by the author 16 May 2017. 